\title{
Vacuum-Assisted Biopsy
}

National Cancer Institute

\section{Source}

National Cancer Institute. Vacuum-Assisted Biopsy. NCI Thesaurus. Code C47949.

A minimally invasive biopsy method that uses either sterotactic mammography or ultrasound for precise positioning of a vacuum-assisted biopsy probe. 